\title{
APPLICATION OF THE SWAT (SOIL AND WATER ASSESSMENT TOOL) MODEL IN THE RONNEA CATCHMENT OF SWEDEN
}

\author{
I. G. BEKIARIS \\ I. N. PANAGOPOULOS \\ M. A. MIMIKOU
}

National Technical University of Athens

Faculty of Civil Engineering

Department of Water Resources

Iroon Politechniou 5

15780 Zografou, Athens, Greece

Selected from papers presented in $9^{\text {th }}$ International Conference on Environmental

Science and Technology (9CEST2005)

1-3 September 2005, Rhodes island, Greece

*to whom all correspondence should be addressed

e-mail: enveco@hol.gr

\begin{abstract}
The subject of this article is the estimation of quantitative (hydrological) and qualitative parameters in the catchment of Ronnea $\left(1800 \mathrm{Km}^{2}\right.$, located in south western Sweden) through the application of the Soil and Water Assessment Tool (SWAT). SWAT is a river basin model that was developed for the U.S.D.A. Agricultural Research Service, by the Blackland Research Center in Texas. The SWAT model is a widely known tool that has been used in several cases world-wide. It has the ability to predict the impact of land management practices on water, sediment and agricultural chemical yield in large complex watersheds. The present work investigates certain capabilities of the SWAT model which have not identified up to now. More in specific, the main targets of the work carried out are the following:

- Identification of the existing hydrological and qualitative conditions

- Preparation - Processing of data required to be used as input data of the model

- Hydrological calibration - validation of the model, in 7 subbasins of the Catchment of Ronnea

- Estimation and evaluation of the simulated qualitative parameters of the model
\end{abstract} All available data were offered by the relevant Institutes of Sweden, in the framework of the European program EUROHARP. The existing conditions in the catchment of Ronnea, are described in detail including topography, land uses, soil types, pollution sources, agricultural management practices, precipitation, temperature, wind speed, humidity, solar radiation as well as observed discharges and Nitrogen and Phosphorus substances concentrations. Most of the above data were used as input data for the application of SWAT model. Adequate methods were also used to complete missing values in time series and estimate additional parameters (such as soil parameters) required by the model.

Hydrological calibration and validation took place for each outlet of the 7 subbasins of Ronnea catchment in an annual, monthly and daily step. The calibration was achieved by estimating parameters related to ground water movement and evaluating convergence between simulated and observed discharges by using mainly the Nash \& Sutcliffe coefficient (NTD). Through the sensitivity analysis, main parameters of the hydrological simulation, were detected. According to the outputs of the SWAT model, the water balance of Ronnea catchment was also estimated.

Hydrological calibration and validation is generally considered sufficient in an annual and monthly step. Hydrological calibration - validation in daily step, generally does not lead to 
high values of the NTD indicator. However, when compared to results obtained by the use of SWAT in Greece, a relatively high value of NTD is achieved in one subbasin. Finally, a comparison between the simulated and observed concentrations of total Phosphorus and Nitrogen was carried out.

KEYWORDS: Hydrological modeling, water resources management, water quality

\section{INTRODUCTION}

The protection of the inland water quality, which constitutes one of the main aims of the European Environmental Policy (Directive 2000/60/EC), is directly related to the spatial and temporal distribution of water quantity. Protecting or improving the inland water quality, presupposes a good knowledge of the hydrological conditions and the relations between the human activities and their contribution to water quality characteristics.

Ronnea catchment is located in southwestern area of Sweden, amongst the cities Helsinborg, Malmo and Solvesborg. It covers an area of almost $1800 \mathrm{Km}^{2}$ and flows to the Baltic Sea area, between the Swedish southwestern coastline and the Danish northeastern coastline. According to World Geographical System (WGS) the outlet of Ronnea has the following coordinates N 56 $16^{\prime} 38^{\prime \prime}$ end E $12^{0} 47^{\prime} 55^{\prime \prime}$.

The catchment is comparatively densely populated with $\sim 100000$ inhabitants, out of which $\sim 70000$ live in cities. The area is generally considered one of the most favorable for agriculture in Sweden

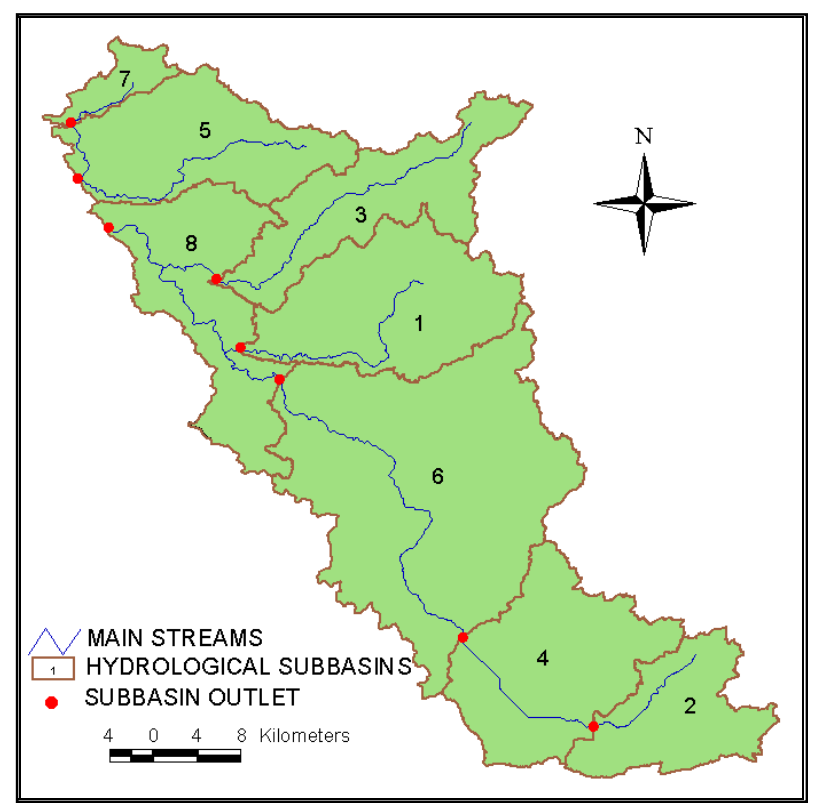
due to the highly fertile soils. The biggest lake is the Lake Ringsjö in the south-eastern part of the catchment.

\section{MODEL DESCRIPTION}

What distinguishes SWAT from common techniques used to estimate runoff is that it is a physical model. The model takes into account such data as climate, soil properties, topography land cover and management and produces outputs with the use of hydrological and other equations. Apart from the ability to incorporate land use and soil data, SWAT differs from other physical models in its ability to separate the watershed into sub-basins and Hydrological Response Units (HRUs). The main basin is divided into smaller ones, by selecting points on the stream network that act as outlets. In this way, the model can provide output data, such as discharge, at specific points of the river network.

SWAT incorporates some of the most common hydrological equations for the simulation of flow. For the accurate implementation of these equations, detailed input data are needed. Of significant value to the simulation are the digital elevation model (DEM) of the watershed, the soil and land use data and the climatic data of the area. SWAT tracks the movement and transformation of several forms of nitrogen and phosphorus in the watershed. These are governed by the nitrogen and phosphorus cycles (Mineralization, Decomposition, Immobilization, denitrification, volatilization etc). Nutrient estimations require knowledge of pollution point sources and agricultural management practices 
(fertilization, tillage etc.). The SWAT in-stream water quality algorithms incorporate constituent interactions and relationships used in the QUAL2E model.

\section{CALCULATIONS PERFORMED \\ Preparation of input data}

The relief of the catchment is generally smooth. Elevation ranges from 0 to $223 \mathrm{~m}$ and the major area is between 25 and $100 \mathrm{~m}$. According to the European Project CORINE LANDCOVER 6 discrete landcover types are encountered in the Ronnea watershed. These types were corresponded with the following land uses incorporated in the SWAT database: Forest, Wetland, Water areas, Agricultural land, pasture, residential area. Forest and agricultural land cover most of the study area ( $46 \%$ and $32 \%$ respectively). According to the soil data four soil types are encountered in Ronnea catchment. All of these types are characterized by significant portions of sand and therefore relatively high hydraulic conductivity. Estimation of soil parameters, by taking into account existing soil measurements, were also taken place. Such parameters are drainage, soil depth, texture, soil bulk density.

The simulation of quantitative parameters require data related to the nutrient loadings which are disposed to the stream network of the catchment area. Nutrient loadings derive either from pollution point sources as well as from diffuse sources. As for the pollution point sources, locations, daily discharges as well as daily total nitrogen and phosphorus concentrations were available for Waste Water Treatment Installations and industrial plants. As for the diffuse pollution sources, available data related to agricultural practices also entered to the model (organic and chemical fertilizer composition, quantities of used fertilizers per unit area, dates of sowing, harvesting, tillage and fertilizer applications).

Sufficient precipitation and temperature data were available by 24 Meteorological stations from which 7 are located into or near the border of the Ronnea catchment. Time series were mostly from January 1981 until December 2001. Other time series used concern wind speed, solar radiation and relative humidity. It is mentioned that despite of estimating representative precipitation for the whole catchment area, the most representative meteorological time series were used for the hydrological simulation of each subbasin. The method of "inverse distances" was used for completing missing values of precipitation time series whereas the "average" method was used for completing missing values of other climatological time series. Measured discharges have also been processed to obtain results of their daily, monthly and annually characteristics for each of the 7 sub-basins (as there were not trustworthy discharge measurements for the outlet of the subbasin 7, no calibration - validation took place for this subbasin).

There is a sufficient number of sampling stations, where qualitative measurements are taken in the Ronnea catchment. The measurements concern mostly total nitrogen and phosphorus concentrations. Lengths of available time series varies amongst stations. Sampling is carried out mainly once a month. Mean monthly concentrations of total Nitrogen fluctuates between 1.5 and $4 \mathrm{mg} \mathrm{l}^{-1}$ (except the outlet of subbasin 2 which present concentrations between 4 and $\left.6 \mathrm{mg} \mathrm{l}^{-1}\right)$. Mean monthly total Phosphorus concentrations varies between 0.035 and $0.13 \mathrm{mg} \mathrm{l}^{-1}$. However in some periods much higher concentrations of total $\mathrm{N}$ ( up to $18 \mathrm{mg} \mathrm{l}^{-1}$ ) and $\mathrm{P}$ (up to $0.5 \mathrm{mg} \mathrm{l}^{-1}$ ) have been measured.

\section{Calibration - validation of hydrological simulation}

Hydrological calibration of the model was implemented according to the following rules: a) Hydrological calibration was attempted separately for the outlets of the 7 studied subbasins of the Ronnea catchment. If a broader subbasin includes other smaller subbasins, calibration of the smaller subbasin precedes and it is incorporated in the calibration of the broader sub-basin and b) Hydrological calibration takes place, by adjusting values of groundwater movement parameters. The simulated discharges were compared to the observed on an annual, monthly and daily time step with the use of 
several indexes and mainly the Nash \& Sutcliff indicator (NTD). It should be noted that although the model run for years 1980 to 2001, the first years (3-5) were disregarded in the calibration process, since they are required by the model as a warm-up period. This period is used for the estimation of several parameters of the model, the initial values of which were not known. Time series were also be partitioned to the calibration and validation periods, for each subbasin.

\section{Qualitative simulation}

According to the initial results of the qualitative simulation there was an underestimation of total Nitrogen simulated concentrations in all subbasins. Phosphorus simulated concentrations presented a better convergence in relation to existing measurements. However, better convergence was achieved by adjusting specific parameters of the model, related to $\mathrm{N}$ and $\mathrm{P}$ concentrations in groundwater.

\section{RESULTS}

Hydrological Calibration - Validation of the model, Qualitative simulation

The following table, presents the values of NTD indicator, for the calibration and validation phases, in an annual, monthly and daily time step according the simulation of the 7 sub-basins.

Table 1. Values of NTD indicator for the hydrological calibration and Validation phases

\begin{tabular}{|c|c|c|c|c|c|c|c|c|}
\hline \multirow[b]{3}{*}{$\begin{array}{c}\text { Sub- } \\
\text { basins }\end{array}$} & \multirow[b]{3}{*}{$\begin{array}{c}\text { Subbasin } \\
\text { area }\left(\mathrm{Km}^{2}\right)\end{array}$} & \multirow{3}{*}{$\begin{array}{c}\text { Catchment } \\
\text { area } \\
\text { including } \\
\text { up-hill } \\
\text { subbasins } \\
\left(\mathrm{Km}^{2}\right)\end{array}$} & \multicolumn{6}{|c|}{ Values of NTD indicator } \\
\hline & & & \multicolumn{3}{|c|}{ Calibration phase } & \multicolumn{3}{|c|}{$\begin{array}{l}\text { Validation phase } \\
\end{array}$} \\
\hline & & & $\begin{array}{c}\text { Annual } \\
\text { time } \\
\text { step }\end{array}$ & $\begin{array}{c}\text { Monthl } \\
\text { y time } \\
\text { step }\end{array}$ & $\begin{array}{c}\text { Daily } \\
\text { time step }\end{array}$ & $\begin{array}{c}\text { Annual } \\
\text { time } \\
\text { step }\end{array}$ & $\begin{array}{l}\text { Monthl } \\
\text { y time } \\
\text { step }\end{array}$ & $\begin{array}{c}\text { Daily time } \\
\text { step }\end{array}$ \\
\hline 1 & 237,6 & 237,6 & 0,50 & 0,57 & 0,21 & 0,54 & 0,24 & $<0$ \\
\hline 2 & 140,6 & 140,6 & 0,50 & 0,41 & 0,13 & 0,64 & 0,34 & 0,15 \\
\hline 3 & 185,1 & 185,1 & 0,12 & 0,48 & 0,26 & 0,41 & 0,19 & $<0$ \\
\hline 4 & 239,9 & 380,5 & 0,66 & 0,51 & 0,08 & 0,59 & 0,40 & 0,13 \\
\hline 5 & 204,7 & 241,5 & 0,40 & 0,55 & 0,13 & 0,77 & 0,65 & 0,20 \\
\hline 6 & 535,3 & 915,8 & 0,47 & 0,67 & 0,44 & 0,68 & 0,43 & 0,15 \\
\hline $7^{*}$ & 36,8 & 36,8 & - & - & - & - & - & - \\
\hline $8^{* *}$ & 211,9 & 1550,4 & 0,14 & 0,66 & - & 0,70 & 0,36 & - \\
\hline
\end{tabular}

* Trustworthy measured discharged data does not exist (no calibration - validation took place)

** No available daily data. Monthly data were estimated by taking into account precipitation, discharges of uphill sub-basins and representative discharge coefficient from neighboring subbasin.

According to the outputs of the SWAT model, the main parameters of the water balance of the Ronnea catchment were also estimated (simulation period 1986-2001). The mean annual rainfall and snowfall come up to $1369 * 10^{6} \mathrm{~m}^{3}$ and $123^{*} 10^{6} \mathrm{~m}^{3}$ respectively. As for the outflows of the water balance a significant percentage $(39 \%)$ percolates to the shallow and deep aquifers (the contribution of the groundwater to the runoff has been abstracted). The runoff percentage comes up to $43,3 \%$, whereas the actual evapotranspiration and the remaining water in soil come up to $8,4 \%$ and $8,9 \%$ respectively.

As for the qualitative simulation, a quite good convergence was achieved for most of the subbasins, by adjusting model parameters concerning the concentrations of $\mathrm{NO}_{3}$ and Soluble $\mathrm{P}$ in groundwater contribution to stream flow (see figure 2). 

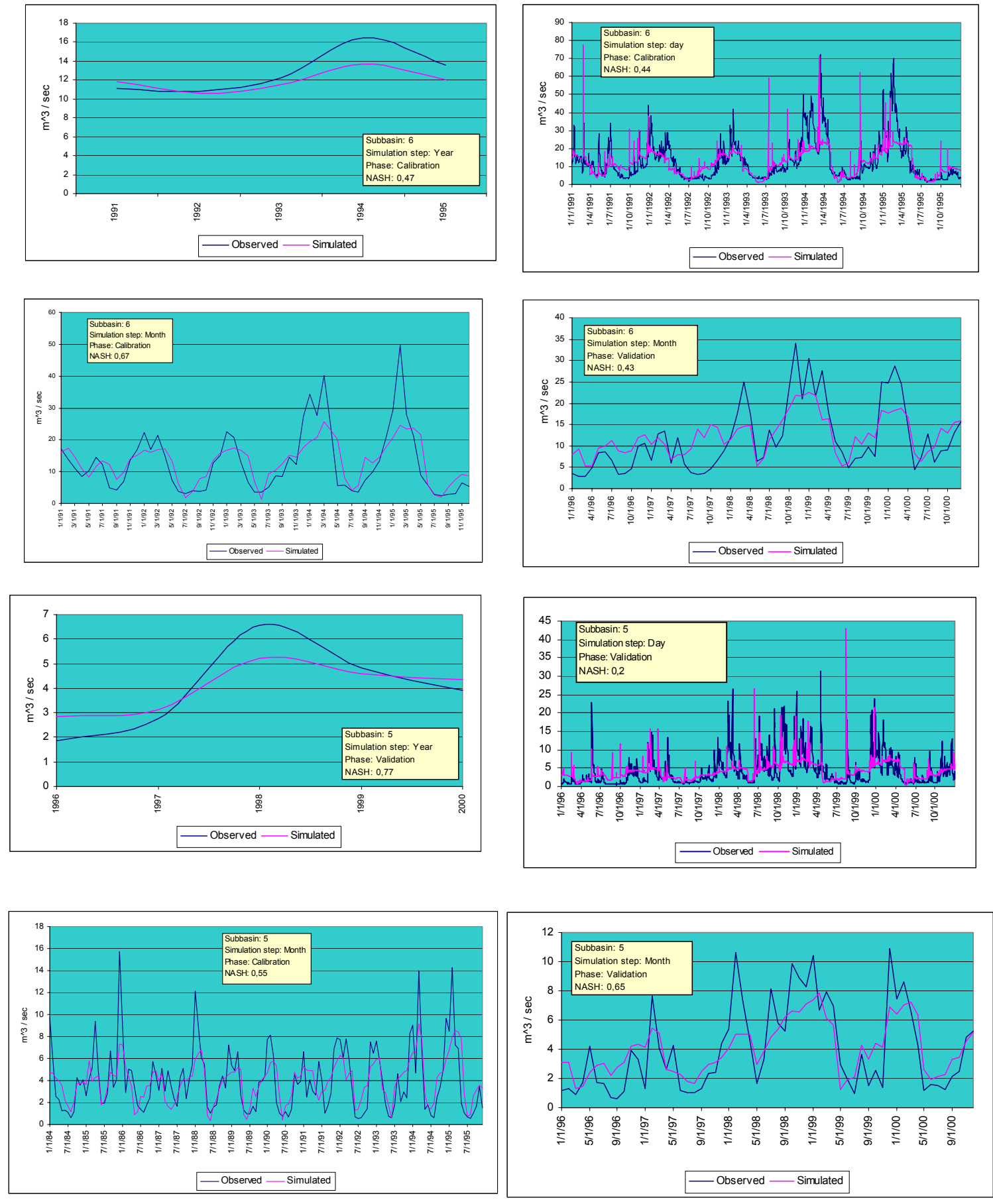

Figure 1. Indicative results of the hydrological calibration - validation (outlets of the subbasins 6 \& 5)
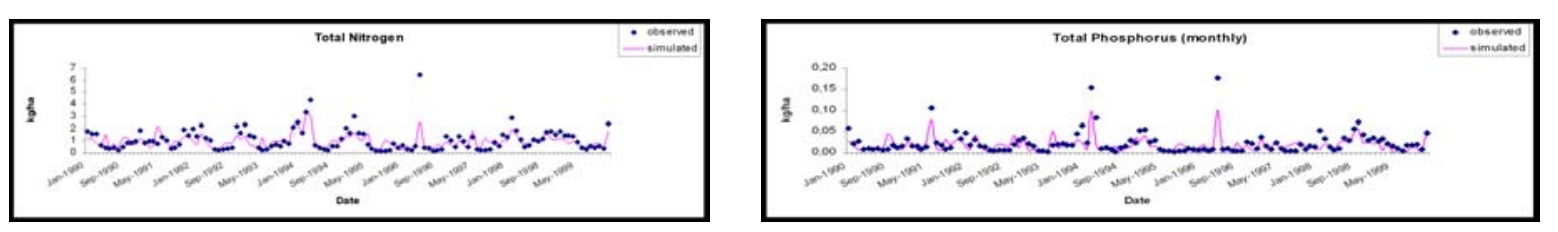

Figure 2. Indicative monthly results of the qualitative simulation (outlet of subbasin 8) 


\section{MAIN CONCLUSIONS}

- The SWAT is characterized as a flexible model, adaptable to different hydrometeorological, soil and land use conditions.

- A basic deficit of the model is that it does not provide tools for the estimation of calibration indicators, such us NTD indicator.

- The use of representative meteorological data for each of the 7 sub-basins generally leads to higher convergence between observed and simulated values. However, meteorological data of doubtful validity may lead to significant divergence.

- The estimated values of the ground water movement parameters are quite similar for almost the entire Ronnea Catchment. This is due to the fact that the hydrogeologic conditions of the catchment do not vary significantly.

- Hydrological calibration and validation at an annual time step, generally leads to sufficient NTD indicators and subsequently to convergence between observed and simulated discharges.

- Calibration at a monthly time step, generally leaded to sufficient values of NTD indicator. Maximum value of NTD indicator were achieved for the sub-basin 6 and came up to 0,7 for the period 1992-1997.

- Validation at monthly time step presented a relevant reduction of NTD indicator. This is likely due to either the need of additional calibration of the hydrological simulation or the existence of not representative meteorological data.

- The calibration - validation at daily time step, generally does not lead to high values of NTD indicator. However, when compared to results obtained by the use of SWAT in Greece, a relatively high value of NTD is estimated for the subbasin $6(0,44)$.

- According to calibration and validation results, the smaller catchment area in south Sweden, for which a good calibration at monthly and annually time step (NTD >0,5) can be achieved with SWAT, comes up to $250 \mathrm{Km}^{2}$.

- According to calibration and validation results, the smaller catchment area in south Sweden, for which a good calibration at daily time step (NTD >0,4) can be achieved with SWAT, comes up to $1000 \mathrm{Km}^{2}$.

- The calibration through SWAT model in a basin greater than $1000 \mathrm{Km}^{2}$, requires meteorological time series with a length of at least 12-15 years, whereas observed time series of measured discharges are essential for the last 5-6 years. This area can be further reduced if there are trustworthy and representative meteorological data.

- The nutrient calibration, of total $\mathrm{N}$ and $\mathrm{P}$ can be achieved through the application of SWAT model in annual and monthly simulation step. Future use of additional data (contribution of pond and lakes to river nutrient concentrations, stock raising, disposal of untreated waste water), can lead to better convergence between simulated and observed values

\section{REFERENCES}

1. Arnold J.G., Williams J.R., Srinivasan R., Neitsch J.G., Kiniry J.R. (2002) Soil and Water Assessment Tool, User's Manual

2. Arnold J.G., Williams J.R., Srinivasan R., Neitsch J.G., Kiniry J.R. (2002) Soil and Water Assessment Tool, Theoritical Documentationl

3. Bedient B.P., Huber W.C. (1992) Hydrology and Floodplain Analysis - Second edition, Addison Wesley

4. Mimikou A.M. (1994) Water Resources Technology - in Greek - second edition, Papasotiriou - Athens

5. Panagopoulos N.I. (2004) Soil investigation for the improvement of SWAT's precision in assessing land use change impact in the Thessaly plain Post-graduate study - National Technical University of Athens 